\title{
Recuerdo del recuerdo \\ (Las "relaciones" de unas fiestas barrocas españolas)
}

Las fiestas institucionales han sido durante la Edad Moderna en España uno de los vehículos fundamentales a través de los cuales se han comunicado los distintos "cuerpos" integrantes de la sociedad estamental, e instrumento usado consciente o inconscientemente por el poder para hacer partícipe a la población de sus propias ideas e intereses. Al mismo tiempo, en su organización y estructura actúan como expresión de la composición y aspiraciones de la sociedad ${ }^{1}$. Se trata de actos en los que, aunque existen numerosas expresiones de carácter popular, la mayor parte de sus componentes se encuentran intensamente normalizados, controlados y ritualizados.

Habitualmente se hace hincapié sobre la naturaleza "dirigida" de éstas y otras formas de la cultura barroca española, que se inscriben casi exclusivamente en una dialéctica de intereses sociales, orquestada invariablemente por el poder. Se trata de un método de acercamiento que se ha mostrado muy útil, pero demasiado vinculado a intereses actuales, por lo que se hace ya necesario ampliar las perspectivas para el estudio de las manifestaciones festivas y ceremoniales, que - dada la riqueza y complejidad de estos actos - son susceptibles de extenderse indefinidamente. Así, por ejemplo, hay que recalcar la posibilidad de estudiar las fiestas no sólo en lo que tienen de auténtico espejo de la imagen que la sociedad que las organiza tiene (o desea difundir) de sí misma y de su historia, sino también -y es una de las múltiples opciones- en lo que tienen de símbolo de las aspiraciones de esa misma sociedad a ordenar, controlar,

1 La parte más significativa de la bibliografía general sobre fiestas en España hasta 1992 ha sido recogida en el catálogo de la exposición Verso e imagen (Madrid: Calcografía Nacional y Comunidad de Madrid, 1993), pp. 257-262. Entre las publicaciones generales posteriores destacan el catálogo de la exposición Barroco español y austríaco. Fiesta y teatro en la Corte (Madrid: Museo Municipal, 1994); Reyes EsCALERA, La imagen de la sociedad barroca andaluza (Málaga: Universidad, 1994); o el volumen VI de la revista Semata, dedicado a "El rostro y el discurso de la fiesta". 
jerarquizar y "normalizar", tanto las relaciones entre sus distintos estamentos como su moral o el entorno natural ${ }^{2}$.

Los acontecimientos que estaban en el origen de las fiestas institucionales podían ser de naturaleza muy variada, y tenían fundamentalmente que ver con la religión, la monarquía, la política o la vida municipal ${ }^{3}$. Algunos eran de carácter conmemorativo, y entre ellos destaca la subida a los altares de héroes religiosos locales, que daba pie a notables celebraciones en las que se rememoraban los acontecimientos más importantes de su biografía. A través de un gran despliegue iconográfico en forma de pinturas y esculturas, mediante numerosos actos de naturaleza dramática o teatral, y por medio de referencias arquitectónicas efímeras, procesiones o actos literarios, se trataba de difundir una imagen del santo, sus virtudes y su biografía que tuviera una dimensión ejemplar y de acuerdo con los intereses religiosos e incluso políticos del momento. La fiesta es, en este caso, un "recuerdo" interesado de una vida, cuyos caracteres sufren un proceso de selección. La gran importancia que se concedía a este tipo de actos dio origen a una abundante literatura que tiene caracteres específicos y está encaminada a dejar testimonio a la posteridad de las celebraciones. Son las llamadas "relaciones de fiestas", en las que, como queremos mostrar en estas páginas, vuelve a producirse un proceso de selección interesada respecto a lo que realmente ocurrió en las celebraciones.

LAS "RELACIONES DE FIESTAS"

Con el siglo xvi empiezan a aparecer pequeñas obras que ya tratan de una manera autónoma sucesos del tipo de las fiestas. Con el tiempo su extensión y ambiciones editoriales aumentaron. Prueba de ello es la relación que escribió Calvete de Estrella del viaje del entonces príncipe Felipe a los países Bajos o la del túmulo sevillano de este mismo personaje. Sin embargo, fue a partir del siglo xvil cuando su número se hizo verdaderamente considerable. También el volumen de información que

\footnotetext{
2 No es éste el lugar más apropiado para desarrollar estos temas, sobre los que hemos insistido anteriormente en La antigua procesión del Corpus Cbristi en Madrid (Madrid: Comunidad de Madrid, 1993); y en "El retrato vivo: Fiestas y ceremonias alrededor de un rey y su palacio", Catálogo de la exposición El Real Alcázar de Madrid (Madrid: Nerea, 1994), pp. 112-130.

3 Un inventario de sus tipologías en José María DfEz BORQue, "Relaciones de teatro y fiesta en el barroco español, en la obra coordinada por él: Teatro y fiesta en el Barroco. España e Iberoamérica (Barcelona: Serbal, 1986), pp. 11-40.
} 
aportaban era por lo general mayor, así como el número de ellas cuidadosamente editadas. Otro hecho a destacar es la incorporación, aunque tímida, de información gráfica a estas obras. Es bastante significativo de la importancia que adquirió el género en este siglo el que uno de los grandes hitos de la historia del libro barroco espanol sea precisamente la relación de Fernando de la Torre Farfán de las fiestas sevillanas de 1671 en honor de San Fernando. Desde un punto de vista estadístico, lo que hemos dicho se hace evidente al contrastar las poco más de cien relaciones de fiestas que fueron editadas en Espana hasta 1600, según el recuento de Mercedes Agulló ${ }^{4}$, con las 352 que, relativas sólo a Madrid y a la primera mitad del siglo xviI, ha encontrado José Simón Díaz

Con frecuencia se han señalado las grandes afinidades que guardan entre sí las relaciones, y así ha podido escribir Bonet Correa que "quien ha leído una relación puede decir que ha leído todas" ", refiriéndose al tono y a la voluntad que las anima, así como a los recursos expresivos y descriptivos. Sin embargo, la variedad es grande tanto en lo que se refiere a las características formales (que oscilan entre las de las producciones equiparables a los pliegos de cordel y las de gran suntuosidad y extensión), como a la personalidad del autor (frecuentemente anónimo, pero en ocasiones de gran prestigio intelectual), o a la calidad literaria del producto.

En cuanto a la voluntad que preside el nacimiento de una relación, se pueden hacer varias clasificaciones. Encontramos desde aquellas que apenas pretenden otra cosa que informarnos someramente del desarrollo de un hecho festivo hasta las que buscan mayor precisión y añaden comentarios, que en ocasiones se convierten en disgresiones muy extensas por parte del autor. Pero todas comparten sin excepción un mismo tono laudatorio hacia la celebración y sus organizadores, que se expresa frecuentemente a base de la multiplicación de los adjetivos calificativos. Es rarísimo encontrar una actitud crítica, que sólo aparece en literatura privada como los Avisos de Barrionuevo o, aunque muy veladamente, en alguna de las cartas de los jesuitas?

- Mercedes Agulló, Relaciones de sucesos. I (1477-1619) (Madrid: CSIC, 1966).

5 José Simón DíAz, Relaciones de actos públicos celebrados en Madrid. 1541-1650 (Madrid: IEM, 1982).

- Antonio BONET CORREA, "La fiesta barroca como práctica del poder", Diwan. núm. 5-6 (1979), p. 57.

7 Escribe el padre González al padre Pereyra el 29 de junio de 1629, después de avisarle de la posibilidad de una invasión del ejército de Condé por Navarra: "Y en el Retiro arden en sol y fiestas, entre todos estos afanes, y el mayor es ahora abrir un brazo de mar de allí a Atocha", Cartas de algunos Padres de la Compañia de Jesús (Madrid: Academia de la Historia, 1861-1865), II, p. 444. 
Hay un tercer tipo de relaciones diferentes a las anteriores, por cuanto no buscan constituirse en recordatorio más o menos fiel del acto, sino que se trata de "programas" previos a la celebración de las fiestas e incluyen una descripción de lo que el lector se encontrará cuando éstas se desarrollen, a la vez que explicaciones sobre la iconografía prevista. Es muy interesante compararlas con los otros tipos de relaciones, y comprobar que lo único que las diferencia es el empleo del futuro, lo que conduce a sospechar que una gran parte de los relatos que sobre fiestas conservamos nos ofrecen la imagen ideal y programada de ellas, y no su verdadero desarrollo, omitiendo imperfecciones que indudablemente hubo.

No se ha hecho hincapié en la existencia de estos "programas", debido sobre todo a su escasez. Dentro del ámbito ibérico conocemos referencias a varios. Uno de ellos describe lo que la Compañía de Jesús tenía previsto hacer en Lisboa para celebrar las canonizaciones de los santos Ignacio y Francisco Javier entre los días 30 de julio y 7 de agosto de 1622. La tasa data del 28 de julio. Faltan en la relación explicaciones iconográficas, y según su anónimo autor estaba destinada a saciar la curiosidad de los forasteros (se supone españoles, pues está redactada en castellano) que querían tener noticias de lo que una ciudad de tanto prestigio en cuestiones festivas pensaba hacer en semejante ocasión ${ }^{8}$.

Otro de estos "programas" no se conserva, pero de él nos ha dejado noticia Alonso Remón en su descripción de las fiestas con que celebró Madrid la canonización de San Pedro Nolasco en 1629. Frente al Alcázar, en uno de cuyos balcones se encontraba el rey, desfilaron una serie de "triunfos" de complicada iconografía. Para su comprensión "antes se había dado de parte de la religión el significado de todos en estampa que tenían caballeros en presencia de Sus Majestades" ".

Por su abundancia y sus numerosos caracteres diferenciadores las relaciones de fiestas forman una especie de subgénero literario, que en España ha sido objeto de algunos trabajos parciales como los de López Estrada, Bonet o José Simón ${ }^{10}$. Se trata por lo general de estudios basados

\footnotetext{
* Relación de las fiestas que la Compañia de lesís en la ciudad de Lisboa hace a la Canonización de S. Ignacio de Loyola su fundador, y de S. Francisco Xavier Apóstol del Oriente (Lisboa: Geraldo da Vinha, 1622).

" Las fiestas [...] que hizo [...] la Merced [...] de Madrid a [...] San Pedro Nolasco este año de 1629 (Madrid: Revista Estudios, 1985), p. 150.

10 Antonio BONET, op. cit.; José SIMÓN, Relaciones de actos públicos..., op. cit.; Francisco LOPEZ EstradA, "Fiestas y literatura", Insula, núm. 470-471 (1986). Para el ámbito italiano, véase R. DíEz, Il trionfo della parola. Studio sulle relazioni di feste nella Roma barocca. 1623-1667 (Roma: Bulzoni, 1986); y Maurizio Faglolo y Silvia CARANDINI, LEffimero barocco (Roma: Bulzoni, 1978).
} 
en las características "inmediatas" de las relaciones, y en los que raramente se utiliza material comparativo con el que contrastar los datos que ofrece la letra impresa (entre otras cosas porque no abundan los estudios sobre fiestas realizados mediante documentación de archivo). Esto puede llevar a veces a equiparar las fiestas con lo que sus relaciones dicen que fueron, olvidando que éstas, dada la procedencia e intereses de sus autores, se escriben casi siempre a posteriori, y en ellas se trata de ofrecer una visión ideal y ordenada de las celebraciones, que por supuesto nunca coincide con la que tuvieron los propios espectadores ${ }^{11} \mathrm{y}$ no siempre se atiene al desarrollo concreto de los acontecimientos.

Es necesario considerar las relaciones de fiestas no tanto como vehículos para describirlas cuanto como "complementos", en el sentido de que nos ofrecen una imagen -ordenada, explicada y racional de una serie de actos que el espectador contemplaba de forma discontinua, incompleta y generalmente confusa, y que en muchas ocasiones no se sucedieron tal y como nos lo cuentan ${ }^{12}$.

El estudio del tipo de información que ofrecen estas obras ha sido objeto de un reciente artículo del profesor Díez Borque, que se ha preocupado en contrastar lo que sobre un mismo juego de cañas dicen varias relaciones ${ }^{13}$. Por nuestra parte, vamos a centrarnos en el análisis de la información escrita que nos ha quedado sobre la que fue, sin duda, la fiesta religiosa coyuntural más importante que tuvo lugar en Madrid en el siglo XVII: la que celebró en 1622 las canonizaciones de los santos Isidro, Teresa, Francisco Javier, Ignacio de Loyola y Felipe Neri.

En otros lugares se ha estudiado el desarrollo de estas fiestas ${ }^{14}$, sobre las que poseemos un volumen de información escrita muy superior al que

11 Hemos tratado del tema en "Religión, poesía e imagen en el Siglo de Oro", en el catálogo de la exposición Verso e imagen. Del barroco al Siglo de las Luces (Madrid: Calcografía Nacional y Comunidad de Madrid, 1993), pp. 311-323.

12 Véase W. MCAllister JOHNSON, "Essai de critique interne des livres d'entrées français au XVI siècle», en Jean JACQUOT, Les fétes de la Renaissance (Paris: CNRS, 1975), III, pp. 187-200.

13 José María Díez BorQue, "Los textos de la fiesta: ritualizaciones celebrativas de la relación del juego de cañas", en La fiesta, la ceremonia, el rito (Granada: Universidad y Casa de Velázquez, 1990), pp. 181-193.

14 Virginia Tovar, Arquitectura madrileña del siglo XVII (Madrid: Instituto de Estudios Madrileños, 1983); Javier PORTús, Fiestas madrileñas por las canonizaciones de 1622 (memoria de licenciatura inédita, Universidad Complutense de Madrid, 1986); Javier PORTús, "La intervención de Lope de Vega y Gómez de Mora en las fiestas por la canonización de San Isidrom, Villa de Madrid, núm. 95 (1988), pp. 30-41; Trinidad DE ANTONIO, .Los artistas en las fiestas madrileñas de 1622 „, Anales de Historia del Arte, III-IV (1993-1994). 


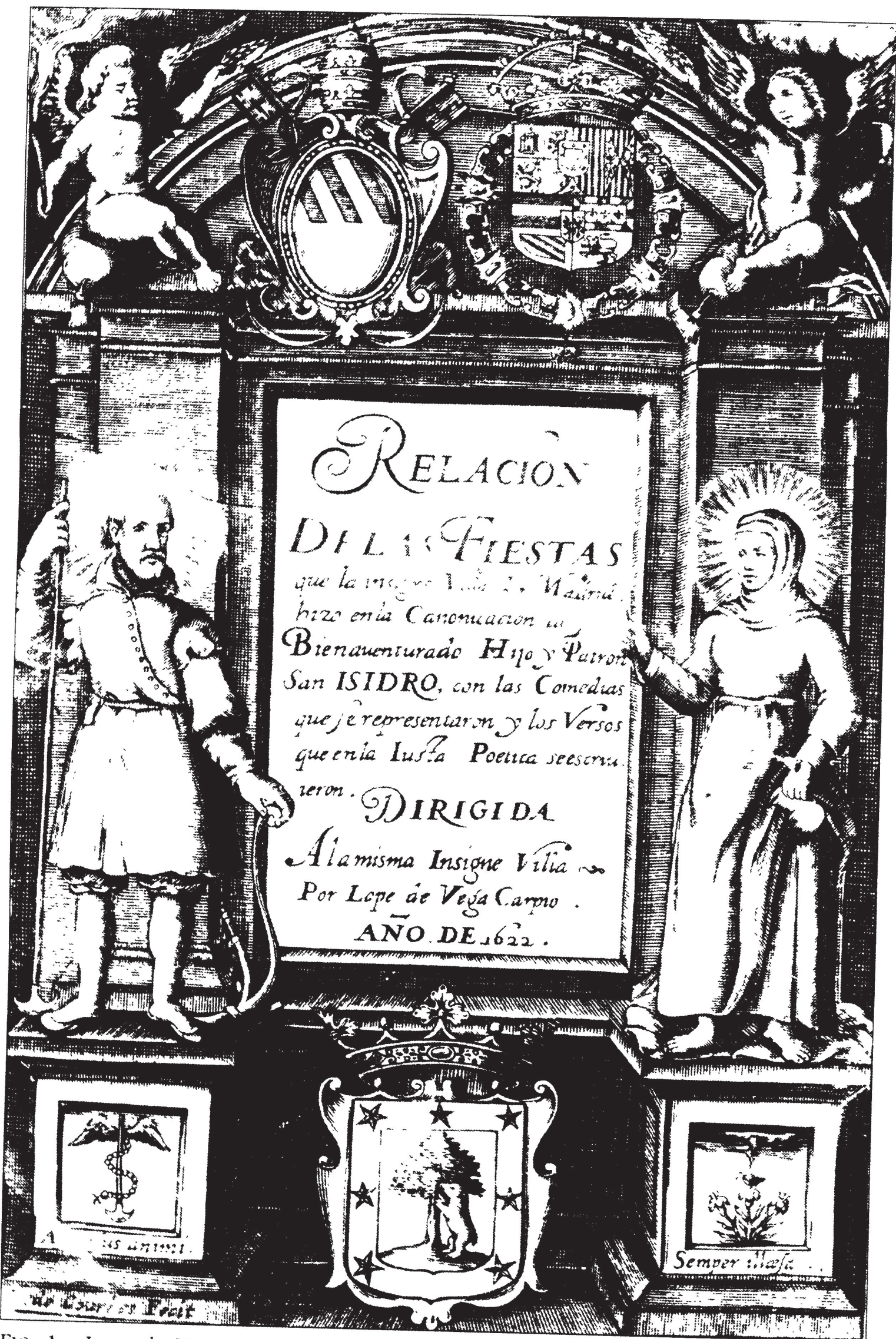

Fic. 1.-Lope de Vega, Relación de las fiestas... de Madrid... en la canonización de. San Isidro, Madrid, Vd. de Alonso Martín, 1622. 
se conoce sobre cualquier otra celebración espanola de esa época, y que se reparte entre un importante conjunto de documentos del Archivo de la Villa de Madrid y del Archivo de Protocolos; varios diarios personales y media docena de relaciones, muy desiguales en lo que se refiere a su extensión, a la personalidad de sus autores y a las características de la información que ofrecen sobre las fiestas.

SOBRE LAS "RELACIONES" DE 1622 Y SUS AUTORES

El importante papel que jugó Lope de Vega en el desarrollo de la cultura del Siglo de Oro ha hecho que de las relaciones que se escribieron sobre las fiestas de las que tratamos haya sido la suya la más conocida y comentada ${ }^{15}$. La calidad literaria del producto y lo cuidado de su impresión lo merecen. Se trata de un tomo en cuarta de 178 hojas. De ellas, las 22 primeras están sin numerar e incluyen, aparte de las tasas y aprobaciones, lo que es propiamente la relación de las fiestas. En el resto de la obra se reproducen las dos comedias encargadas a Lope por el Ayuntamiento, y las poesías que se leyeron en el acto de entrega de premios del certamen poético que organizó la Villa de Madrid ".

La redacción de esta obra le fue encargada a lope el 17 de mayo de 1622, por acuerdo de la comisión del Ayuntamiento para organizar las fiestas, y desde entonces hubo el acuerdo de editarla ${ }^{-}$. Este encargo le fue hecho con cierta anticipación, pues hasta un mes más tarde no se celebraron las fiestas. De hecho, se trató de uno de los primeros acuerdos relativos a las fiestas, anterior a la mayoría de los relacionados con aquellos elementos que acabarían por definirlas; lo que nos da idea de la importancia que tuvieron las relaciones como objetos integrantes de las celebraciones, y no sólo como reflejo de ellas. La consideración de este tipo de obras como objetos festivos tuvo que influir mucho en el carácter de la información que aportan, restándoles objetividad e inclinándoles a dar una imagen ideal de las celebraciones.

No conocemos los pasos que fue dando Lope de Vega para redactar su obra. Su presencia continua cerca de los organizadores tuvo que pro-

15 Véase, por ejemplo, Joaquín ENTRAMBAsaglias, "Las justas poéticas en honor de San Isidro y su relación con Lope de Vega", Anales del Instituto de Estudios Madrileños, IV (1969), pp. 27-133.

16 Relación de las fiestas que la insigne Villa de Madrid bizo a la Canonización de su Bienaventurado bijo y Patrón San Isidro, con las comedias que se representaron y los versos que en la Iusta poética se escrivieron (Madrid: Viuda de Alonso Martín, 1622).

1- Archivo de la Secretaría del Ayuntamiento, 2-272-30, fol. 18v. 
veerle de un caudal de información considerable, que se acrecentaría con lo que percibió directamente durante los actos. Suponemos que durante todo el tiempo posterior al encargo iría tomando notas o reteniendo en su memoria lo que sucedía. Sin embargo, la redacción definitiva tuvo que ser posterior al 28 de junio, que es cuando se fecha otra relación, la de Manuel Ponce. Lope conocía y utilizó ésta cuando escribió la suya, como prueba al indicar que el "jardín" de la plaza de la Cebada fue "obra de muchos días, y no, como algunos piensan, de una noche"; refiriéndose a ella, en donde se considera motivo de asombro la rapidez de la ejecución, en una noche, de esta huerta urbana. En

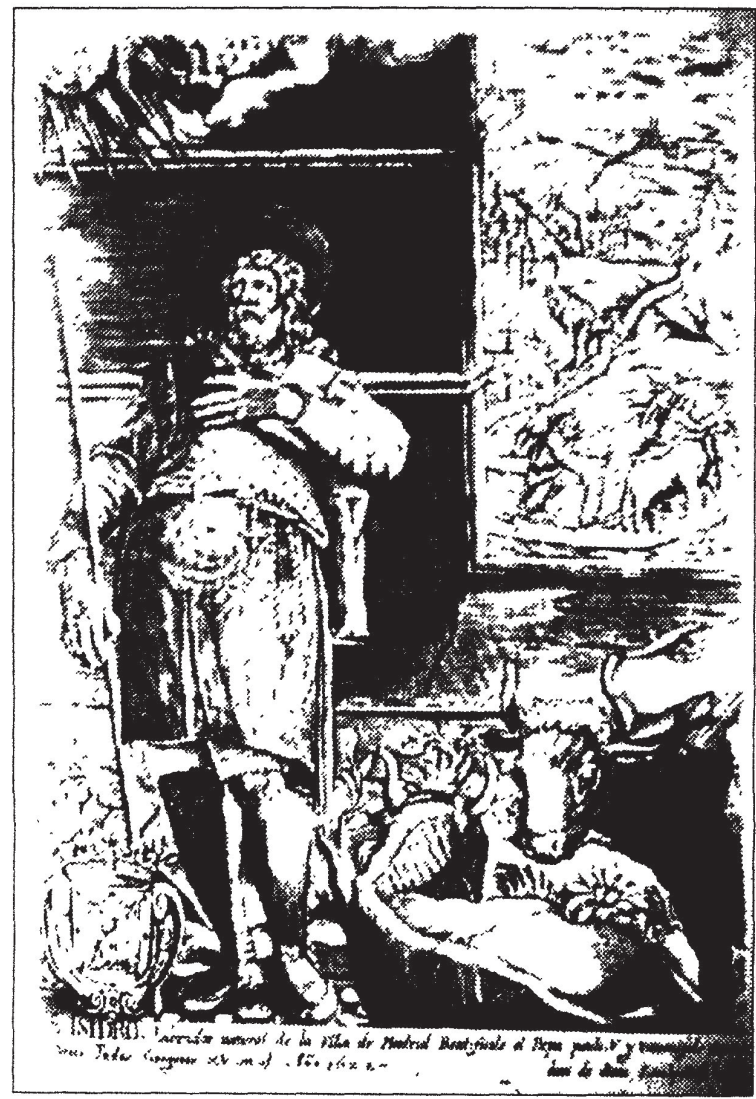

Fig. 2.-Juan de Diesa: San Isidro labrador, 1622 . todo caso, lo que es seguro es que para el 3 de agosto ya tenía escrito su libro, pues en este día se fecha la suma del privilegio.

La segunda gran relación de las fiestas está firmada por Fernando Monforte y Herrera ${ }^{18}$. Es la única vez que aparece este nombre, por lo que se ha pensado que se trata de un pseudónimo. No tiene nada de entraño el uso de un nombre falso en esta obra, pues era bastante corriente entre los jesuitas su empleo, cuando de escritos de esta naturaleza se trataba. Eugenio de Uriarte le identificó como Fernando Chirino de Salazar, basándose en un manuscrito de la Biblioteca Nacional firmado por el "Niño Duende», quien manifiesta que en su infancia le habían admitido algunas obras en certámenes poéticos, "como lo exagera el Padre Salazar en el libro de la canonización de S. Ygnacio y S. Francisco Xabier" ${ }^{19}$. Podemos añadir

18 Fernando MONFORTE y HeRrera, Relación de las fiestas que ba becho el Colegio Imperial de la Compañia de Iesús en Madrid en la canonización de San Ignacio de Loyola. y' San Francisco Xavier (Madrid: Luis Sánchez, 1622). Ha sido reproducida en José SIMón Díaz, Historia del Colegio Imperial de Madrid. I (Madrid: Instituto de Estudios Madrileños, 1952), pp. 183-414.

19 Eugenio URIARTE, Catálogo abreviado de obras anónimas y seudónimas de autores de la Compañia de Jesús (Madrid: Sucesores de Rivadeneyra, 1906), III, p. 424. 
algún dato que confirma esta identificación, como un recibo de agosto de 1622 que demuestra que fue el padre Salazar el encargado de organizar el certamen poético (como Lope de Vega en lo que se refiere al Ayuntamiento) y buscar sus premios; o el hecho de que fuera él quien representó a la Compañía de Jesús en las reuniones con el Ayuntamiento y los carmelitas descalzos para organizar las fiestas ${ }^{20}$. Fernando Chirino de Salazar nació en Cuenca en 1572 e ingresó en la Compañía veinte años más tarde. Fue profesor de gramática y escriturística, predicador de Felipe IV, confesor del Conde-duque y calificador de la Inquisición. Se piensa que fue el inventor del arbitrio del papel sellado y se le atribuye la fundación de los Reales Estudios de la Compañía en Madrid. Según José Simón Díaz, sus contactos cortesanos fueron degradando la disciplina del Colegio Imperial, lo que motivó su traslado de la Corte ${ }^{21}$. Fue un hombre de amplia cultura, como demuestra en algunos de sus escritos de exégesis bíblica ${ }^{22}$.

La obra consta de dos partes bien diferenciadas, como la de Lope, ambas de extensión similar. Una de ellas está dedicada a la descripción de las fiestas, y la otra se ocupa del certamen poético. Incluso sus paginaciones son independientes. La primera es la fuente principal para el conocimiento de las celebraciones de los jesuitas y de los altares de conventos y particulares. En lo que se refiere a la información que aportan, la relación de Lope y ésta (que fueron publicadas por las mismas fechas) se complementan, y de ello son conscientes sus autores. Así el jesuita, que tan cuidadoso es a la hora de describir todos los detalles de la fiesta, evita las descripciones de los obeliscos y remite para su conocimiento "al que tan dignamente celebra las fiestas, que con tanta magnificencia ha hecho la Villa” ${ }^{23}$; y Lope, por su parte, para no dar detalles sobre la Máscara y otros aspectos de las fiestas jesuíticas, nos recomienda "el libro de sus fiestas". En una ocasión, Monforte renuncia a describir los actos organizados por los carmelitas descalzos y remite a la urelación general de todas las fiestas" ${ }^{24}$. No sabemos si se refiere a la de Lope (que, como acabamos de ver, tenía como objeto simplemente las fiestas de la Villa y apenas hace una pequeña mención a la orden de santa Teresa), o si pensaba que se estaba redactando una relación general de todos los actos festivos.

20 Archivo Histórico Nacional, Jesuitas, Libro 313 ("Recibo de agosto de 622").

21 José Simón, Historia del Colegio Imperial..., op. cit., p. 549.

22 Murió en 1646, como indica Carlos GÁlvEz, “Una colección de retratos de jesuitas», Archivo Español de Arte y Arqueología, IV (1928), p. 125, que dio a conocer un retrato suyo.

23 MONFORTE, op. cit., fol. 20r.

24 Idem, fol. $74 \mathrm{r}$. 
Además de éstas, se conservan cuatro relaciones de corta extensión, aunque una de ellas es copia de otra. La más temprana es una anónima editada en Barcelona por Esteban Liveros ${ }^{25}$, un impresor que produjo una considerable cantidad de obras de características formales similares a ésta. Es la más breve de todas, y en ella su autor se limita a narrar lo ocurrido desde el miércoles 6 de abril, cuando llegó a Madrid la noticia de la canonización, hasta el viernes siguiente. Según consta al final, fue escrita el 9 de abril. Aparenta ser una carta privada que ha sido aprovechada por el editor, como indica la frase "de todo como sucediere avisaré a V. M. puntualmente", que aparece al final.

Otra de las relaciones fue escrita por Miguel de León ${ }^{26}$, y a su vez dio origen a una publicada de forma anónima en Sevilla ${ }^{27}$. El texto de ambas es similar, lo que es significativo de los escasos escrúpulos editoriales de la época. Son de corta extensión y se caracterizan por el detalle con que describen los aparatos arquitectónicos y su insistencia en transcribir la epigrafía que en ellos había. Sin embargo, apenas informan sobre los elementos integrantes de la procesión, y nada dicen de las ceremonias de publicación de los premios de los certámenes poéticos. Tampoco, de los espectáculos pirotécnicos y similares. Es posible fechar la redacción de estas obras inmediatamente después del 19 de junio, que es el día en que se celebró la procesión general, pues de lo que se hizo en adelante nada se dice.

La de Manuel Ponce es la más detallada ${ }^{28}$. Comienza directamente a relatar lo acontecido desde el 18 de junio, omitiendo los actos de los días precedentes, y se detiene mucho en la descripción de algunos de los

$\therefore$ Principio de las reales fiestas, desta Corte y Villa de Madrid, en la santa canonización de su glorioso Patrón S. Isidro labrador. con los otros quatro compañeros S. Ignacio de Loyola, Fundador de la Compania de Iestis, y S. Francisco Xavier su compañero. S. Teresa de Iesus Fundadora de los Descalzos Carmelitas. y de S. Phelipe Neri Florentin (Barcelona: Estevan Liberos, 1622). Se reproduce en José Simón, Relaciones.... op. cit.. pp. 16.3-164.

2. Fiestas de Madrid celebradas a XIX de junio de 1622 años, en la canonización de San Isidro. San Ignacio. San Francisco Xavier. San Felipe Neri Clérigo Presbitero Florentino y. Santa Teresa de lesuis (s.1., s.i., s.a.).

- Sumptuosas fiestas que la lilla de Madrid celebró a XIX de Iunio de 1622 en la canonización de San Isidro. San Ignacio. San Francisco Xavier, San Felipe Neri Clérigo Presbitero Florentino, y Santa Teresa de lesuis (Sevilla: Simón Faxardo, s.a.). Se reproduce en SIMON. Relaciones de actos públicos.... op. cit.. pp. 164-168.

28 Relación de las fiestas que se han hecho en esta corte, a la canonización de cinco santos: copiada de una carta que escritió Manuel Ponce (Madrid, Viuda de Alonso Martín, s.a.). Se reproduce en José Simón, Relaciones de actos públicos.... op. cit.. pp. 109-1 178 . 
altares, sobre todo del que hicieron los mínimos de San Francisco de Paula, de cuyos jeroglíficos se declara autor ${ }^{29}$. Alude también, y con cierta extensión, a los actos protagonizados por los jesuitas y a los certámenes poéticos, remitiéndonos para mayor información en el caso de la Compañía al libro "que se imprimirá desta fiesta" ${ }^{30}$. Se puede decir que es ésta la relación más completa de todas, en el sentido de que no deja de tratar - si exceptuamos la celebración de los carmelitas- casi ninguno de los aspectos que conformaron estas fiestas. Además de en su relación y en los jeroglíficos mencionados, encontramos alguna otra huella de su presencia en las fiestas como el soneto "Una Aurora, esplendor de siete Auroras", que presentó al certamen poético del Ayuntamiento ${ }^{31}$. Se trata de un poema de cierta calidad, lo que justifica el elogio a las dotes poéticas de su autor que hizo Lope de Vega un año antes en su Jardín. Parece ser que se trataba de un personaje de cierta cultura, y ello lo demuestra no sólo en esta relación, sino también en algún otro escrito ${ }^{32}$.

\section{ANÁLISIS COMPARADO DE LOS TEXTOS}

De estas obras de corta extensión es interesante el estudio de sus lugares de edición, pues puede aportarnos datos sobre el carácter de este tipo de literatura. Una de ellas apareció editada en Barcelona muy poco después de producirse los hechos que relata, y la impresa en Sevilla también se escribió cuando aún no habían acabado las fiestas; todo lo cual nos habla de un público ávido de tener noticias de unos acontecimientos que, dada la magnitud del hecho que los provocó, se esperaban extraordinarios. Los lugares y tiempo de edición creemos que determinaron el carácter de la información que aportan estas dos relaciones, que resultan bastante asépticas y se limitan a describir algunos de los elementos integrantes de las fiestas. Esto queda en evidencia, sobre todo, al compararlas con las impresas en Madrid. Así, tanto la de Lope como la de Monforte, por su redacción y edición más cuidadas, se convierten no sólo en tes-

29 "Estos hieroglíficos y virtudes con sus inscripciones, ofreció mi devoción a $S$. Francisco de Paula, de quien soy devoto, si son defectuosos son míos, si acertados fueron del santo", op. cit., fol. 5v.

30 Op. cit., fol. $10 \mathrm{v}$.

31 LOPE DE VEGA, op. cit., fol. 92v.

32 Por ejemplo, en su Oración fúnebre a la muerte de don Rodrigo Calderón (Madrid: Viuda de C. Delgado, 1621). Véase Cristóbal PÉREZ PASTOR, Bibliografía madrileña (Madrid, 1891-1907), III, p. 71. 


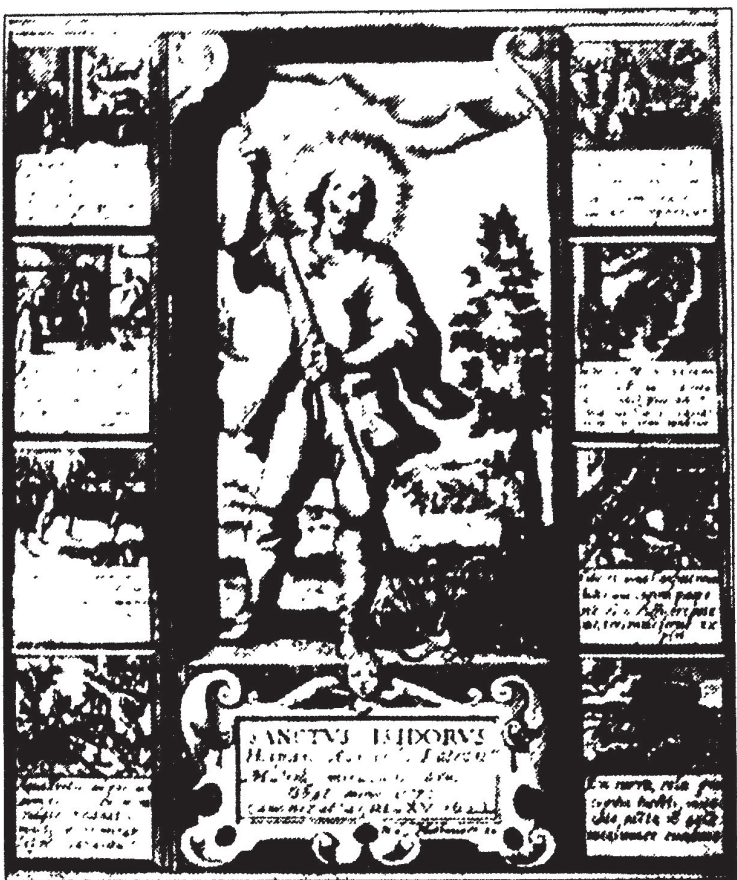

FIG. 3.-Matthoniere: San Isidro labrador 1622.

timonios de unos hechos, sino también en parte y prolongación de la propia fiesta. Han dejado de tener un valor exclusivamente coyuntural y pasan a ser obras dignas de ser guardadas en una biblioteca. Por ello su redacción, además de una enumeración de lo que el escritor percibe, nos ofrece numerosos comentarios personales y una clara voluntad de estilo. Ya hemos dicho que, antes incluso de que el Ayuntamiento madrileño decidiera muchos de los elementos que habrían de conformar las fiestas, encargó a Lope su redacción; y no hay más que repasar algunos de los inventarios de bibliotecas de la época para comprender la importancia que se daba a las relaciones cuidadosamente editadas ${ }^{33}$.

Se pueden diferenciar dos tipos entre los promotores de estas obras. Por una parte el integrado por quienes a la vez son comitentes en las fiestas ${ }^{34}$, y por otra el formado por aquellos cuyas únicas ambiciones son de carácter comercial. Lope de Vega y Monforte escriben sus obras auspiciados por los organizadores de los actos festivos (y en el caso del jesuita él mismo puede considerarse comitente), mientras que el resto parece que lo hacen por su cuenta, o al menos alejados de los centros de organización. El comparar las relaciones a la luz de esta diferencia puede aportar datos de interés, y demuestra que la disparidad de promotores conlleva claramente una diversidad en el aspecto editorial. Las dos primeras están mucho más cuidadosamente impresas y en sí mismas se convierten, además de por su contenido, en objeto prestigiador de quienes las han

33 El inventario de la biblioteca del Condestable de Castilla (In Indicem Librorum. Regium Bibliothecam. Principis Ioan. Fer. Velasci. Biblioteca Nacional de Madrid, Mss. 7840) refleja la existencia de varias relaciones de fiestas: las florentinas por la entrada de Juana de Austria, las milanesas por la de Margarita de Austria, el recibimiento del cuerpo de san Eugenio de Toledo, la entrada en Sevilla de Felipe II, diversas exequias, etc.

34 Véase Fernando MORENo CUADRO, Artistas y mentores del Barroco efimero (Córdoba: Diputación, 1985). 
encargado. Las demás son obras de vida efímera y carecen casi por completo de ambiciones que no sean las estrictamente informativas. Podría pensarse que la independencia respecto a los entes organizadores conduce a una mayor posibilidad de crítica $O$, al menos, a una cierta distancia. Sin embargo, esto no ocurre en nuestro caso, pues el tono se hace igualmente laudatorio en los libros patrocinados por la Villa y los jesuitas y en los editados privadamente.

De los autores es interesante conocer su relación con los organizadores de las fiestas, si han intervenido en éstas, o su cultura. Más adelante comprobaremos que el conocimiento por parte del escritor de lo que había sido proyectado por la organización, y la constatación de sus posibles defectos cuando es llevado a la práctica, no le hace señalar estos errores, sino que se refiere al hecho tal y como fue proyectado. Los autores de las relaciones, sobre todo si han seguido de cerca la organización de las fiestas, tienden a ofrecernos una imagen ideal de éstas, y no una descripción de su verdadero desarrollo.

La participación del escritor en algunos de los elementos de las fiestas puede también determinar algunos de los elementos de su relación. En el caso que analizamos nos encontramos con tres actitudes distintas. Por una parte aparece la de Manuel Ponce, que ya hemos visto se declara autor de los jeroglíficos del altar de los mínimos, y se detiene en su descripción mucho más que en la de cualquier otro. Monforte no se declara autor de nada, aunque por documentación de archivo sabemos que lo fue del Castillo pirotécnico, de la Máscara y del Certamen de la Compañía; pero se hace evidente su proximidad a la organización cuando leemos sus descripciones de los altares, las pinturas o el "Triunfo" de su orden, repletas de comentarios iconográficos y que demuestran el deseo de ofrecer al lector una ordenación racional, tal y como fueron proyectados, de todos estos elementos. Lope de Vega, por el contrario, apenas deja entrever en su relación las numerosas partes de las fiestas que se debieron a su iniciativa.

En general de los autores se puede decir que poseían una cultura amplia, a veces de primera magnitud como Lope, que demuestran no sólo en una redacción correcta y relativamente clara, sino también en los comentarios iconográficos y de filiación cultural que de vez en cuando hacen.

El análisis de algunas de las fuentes utilizadas por los escritores nos puede revelar otros aspectos interesantes de las relaciones. De Lope ya vimos que se valió tanto de su proximidad a la organización de las fiestas como de la relación de Ponce. Monforte tuvo un acceso directo a los preparativos de los actos de la Compañía, e incluso fue el organizador de algunos de ellos; sin embargo, para informarse sobre otros aspectos es posible que 
hiciera uso de las relaciones publicadas anteriormente a la suya. De la importancia que la proximidad del escritor a la organización tiene en la calidad y cantidad de la información es consciente Lope, al remitirnos para el conocimiento de la máscara del 22 de junio a la relación de los jesuitas, "pues ellos solos, que lo supieron trazar, emprender y conseguir con tan general admiración, lo sabrán escribir y celebrar como merecen".

Otras fuentes utilizadas por los escritores recogen la visión directa de los festejos y la opinión del público. La primera es fundamental cuando no se ha participado en la organización, y de su importancia nos ilustra Monforte al excusarse por su imposibilidad de describir con detalle el altar de los trinitarios: "No podré pintarlo en particular, por no averlo visto más de una vez, y bien de paso, y no he tenido relación de su traça, después de averla pedido algunas veces" ${ }^{35}$. La aportación del público como fuente de opinión o incluso de explicaciones es tenida en cuenta por este mismo autor. Así, del "Triunfo" de la Compañía comenta que "a dicho de los más eruditos, pudo oscurecer el de los antiguos romanosn; y de las colgaduras de San Andrés dice que, "según la calificación de todos", son las mejores de la Corte ${ }^{36}$.

Hay un fenómeno que nos parece muy interesante en lo relativo a las fuentes que manejan los escritores, y que se puede documentar con cierta precisión. Nos referimos a la aportación por parte de los artífices de descripciones y trazas de los aparatos que levantaron para las fiestas, sobre todo cuando se trata de altares o de estructuras de carácter arquitectónico. Acabamos de ver un testimonio de Monforte que lo prueba. Por otra parte, el enorme detalle con que nos ofrece sus dimensiones tuvo que obedecer a un contacto con sus autores. Lope ofrece alguna prueba clara de la existencia de estos recursos, como cuando comenta del altar de los mínimos de la Victoria que "se debiera un libro aparte; mas, como en otras relaciones se copiaron los que dieron los arquitectos de su fábrica, no me atrevo a decir lo dichom. Se refiere indudablemente a Manuel Ponce, que ya hemos dicho se declara autor de los jeroglíficos y que ofrece en su relación una descripción enormemente pormenorizada del altar. El mismo Lope al tratar de los obeliscos menciona esta utilización de descripciones y trazas de los artistas, dando a entender que se trataba de un fenómeno generalizado y no sólo particular de las fiestas de $1622^{3^{-}}$.

i5 MONFORTE, op. cit. fol. $27 \mathrm{v}$.

36 Idem, fols. $69 \mathrm{v}$ y $36 \mathrm{v}$.

$3^{-}$"La descripción de sus cuerpos y miembros principales no toca al estilo de relaciones menudamente, por ser ciencia en que pocos saben, y que los más de los que las escriben, en ellas trasladan los diseños de los maestros. 
Las estructuras internas de las relaciones y las técnicas descriptivas utilizadas por sus autores determinan a su vez el carácter de la información sobre las fiestas. El escritor, al estar obligado por razones de método a seguir un esquema determinado -en sus líneas generales, común a casi todas las obras de este género-, debe renunciar a ofrecernos como un cuerpo único aquello que no se sujeta a alguna de sus partes. Así, por ejemplo, las alusiones al público, a la música o a las sensaciones olfativas suelen aparecer (cuando aparecen) totalmente desperdigadas en las páginas de las relaciones, mientras que los aparatos arquitectónicos o las procesiones se tratan autónomamente. La sujeción a un esquema, prácticamente inevitable, condiciona un punto de vista ideal y ordenado que no es precisamente el de los espectadores, que perciben la fiesta como un continuum en el que todos los elementos se amontonan y repercuten en sus sentidos de una manera poco ordenada.

La estructura interna varía en las relaciones de las fiestas de las que estamos tratando. La de Lope es la más institucionalizada y la que, en principio, ofrece menos posibilidades de dar una visión ajustada del hecho festivo, por cuanto se atiene al esquema ordenado que presidió las decisiones de los organizadores y no al desarrollo real de las fiestas. Divide su relación en varias partes, de acuerdo a la naturaleza de los elementos que definieron los actos. En primer lugar, alude a lo que llama "cosas fijas"; de ellas comienza por describir los obeliscos y sigue con los altares, sin tener en cuenta que la ubicación a veces coincidente de éstos y aquéllos podía haber aconsejado una organización topográfica de la descripción. Acaba aludiendo al "jardín" de la plaza de la Cebada, a la valla y a los tablados. En segundo lugar, trata de lo móvil: primero, de los carros; luego, de la procesión, y por último, de los espectáculos pirotécnicos. Acaba su relación aludiendo rápidamente a las fiestas organizadas por los carmelitas, y a las comedias. La comparación de este esquema, y el tipo de información que admite con la documentación que se conserva en el Archivo de la Villa, nos revela que Lope hubiera podido escribir su relación incluso si los actos que describe no se hubieran podido celebrar. Se trata, pues, la suya de una fórmula muy estática, enormemente restrictiva y que impide la plasmación del verdadero desarrollo de las fiestas, pues en ella apenas encajan las menciones al público, y se destierra un factor tan importante como el del tiempo en el que fueron ocurriendo los acontecimientos. Pero, a la vez, es muy reveladora de la verdadera naturaleza de las relaciones de fiestas barrocas, para las que el aspecto informativo - a pesar de que, a veces, se piense lo contrario- es algo subordinable.

Muy restrictivo es también el escrito de Miguel de León, que se limita a describir los altares y obeliscos, y apenas menciona la procesión. Destaca 
su obsesión por transcribir toda la epigrafía. Manuel Ponce se hace con un esquema algo más elástico, en el que mezcla la descripción de los aparatos arquitectónicos con un cierto orden cronológico de los actos para los que éstos sirvieron de escenario.

Monforte es quien parece ofrecer una visión más ajustada del desarrollo de las fiestas, y en gran parte esto es debido a que nos la presenta según un criterio cronológico, lo que le permite no ser demasiado excluyente y dar cabida a un buen número de datos que de las demás relaciones están ausentes. Aunque tanto el relato de Lope como el de Ponce o el de León están condicionados por la necesidad de la brevedad, en el de Monforte no existen limitaciones de este tipo; y ofrece incluso en alguna ocasión la posibilidad de conocer en pocas líneas lo que más adelante desarrollará en muchas páginas. Así, al referirse a la Máscara del "Triunfo" de la Compañía, anuncia: "Pondré brevemente el intento, las personas y carros que iban en general, antes de llegar a tratar de la magestad y grandeza con que fueron, para que el que quisiere satisfacerse de presto, y saber el orden pueda hazerlo brevemente sin esperar a ver mal pintado lo que vio llevarse la admiración de todos" ${ }^{38}$. También este mismo autor evita repeticiones que cree innecesarias. Por eso describe sólo una de las nueve Musas o uno sólo de los pajes de la Máscara. Otras veces se salta el orden cronológico, como en el caso de su descripción de la ceremonia de reparto de premios del certamen de la Compañía, cuando "por no interrumpir el hilo de la relación" deja para el final la enumeración de los laureados y la reproducción de sus poemas ${ }^{39}$.

Hay dos recursos expresivos que se emplean con frecuencia en estas relaciones: el abigarramiento descriptivo y la multiplicación de los adjetivos calificativos. El primero lo utiliza mucho Monforte, que hace uso de relaciones exhaustivas e inacabables de objetos, para sugerirnos la grandeza de las fiestas. Parece querer producir en el lector, por medio de las palabras, la misma sensación que experimentaban los espectadores ante la proliferación de joyas y adornos. Esto ofrece a su relación, y a muchas otras del Barroco español, un cierto carácter de inabarcabilidad; y creemos que se trata de uno de los recursos expresivos mejor aprovechados y que han dado mayores frutos para transcribir la vivencia de un hecho festivo. Las descripciones que hace Monforte de la Máscara de la Compañía son antológicas en este sentido; y aunque sigue en ellas una estructura lógica, el lector, por lo pormenorizado de la enumeración, apenas puede jerarquizar los distintos elementos, que se ofrecen a nuestra mente de

\footnotetext{
38 MONFORTE, op. cit., fol. 40r-v.

39 Idem, fol. $73 \mathrm{v}$.
} 
manera un tanto confusa y seguramente parecida a como los percibían los espectadores. En cuanto a los adjetivos, su función de activadores de la imaginación ha sido puesta de manifiesto por McAllister ${ }^{+0}$ : operan de la misma forma que el abigarramiento enumerativo al que hemos hecho referencia. Con esto se nos ofrece la imagen de la fiesta como un hecho inefable $o$, al menos, no reducible a conceptos empleados habitualmente. Creemos que no se puede explicar la presencia de estos adjetivos sólo como un instrumento de adulación —que también pudo serlo-, sino que hay que ver en ellos además un recurso expresivo tendente a aproximar al lector a la realidad vivida de la fiesta.

Unas celebraciones, sobre las que la documentación es tan abundante y variada, nos pueden informar sobre la exactitud de las fuentes de que generalmente disponemos para el conocimiento de este tipo de actos. El contraste de la información suministrada por las diferentes relaciones revela algunas contradicciones, que afectan sobre todo a interpretaciones y descripciones iconográficas, y a la localización y composición de los aparatos festivos. Así, por ejemplo, mientras que Lope dice que es un azor un ave de un jeroglífico colocado en un obelisco de la Puerta de Guadalajara, Miguel de León cree que es un águila; y esta diferencia afecta completamente al sentido del emblema, que se basa en la comparación de la corta vida de san Luis Gonzaga con la ligereza del vuelo de los azores noruegos ${ }^{41}$. La relación que ofrece mayores inexactitudes y errores es la de Ponce: es el único, por ejemplo, que dice que san Isidro figuraba sobre la nave del altar de los carmelitas, mientras que el resto de los autores lo sitúan en un altar colateral. Más contradicciones aparecen en las descripciones de imágenes: así, del Cristo del altar de los Agustinos Monforte asegura que salían siete listones imitando sangre, mientras que Ponce dice que eran cinco $^{42}$.

En ocasiones los errores son más importantes, como el que comete este escritor al situar los obeliscos de la Puerta de Guadalajara en Puerta Cerrada; y ya hemos visto cómo Lope tuvo que señalar su error al atribuir la construcción de la huerta de la plaza de la Cebada al trabajo de una sola noche. Otras veces es un mismo autor quien se contradice. Así, Monforte justificó en la tardanza de la salida del rey la ausencia de fuegos artificiales el día de la entrega de premios del certamen de la Compañía,

\footnotetext{
40 Op. cit., p. 194.

41 No son éstas, ni mucho menos, las únicas confusiones a que dio lugar la fauna exótica en los autores de relaciones de fiestas en esa época. Sobre algunas de ellas hemos tratado en aLos camélidos andinos y Europa. Imágenes y palabras para una historia de integración cultural", en Oro de los Andes. Las llamas, alpacas, vicuñas y guanacos de Sudamérica (Barcelona: Jordi Blassi, 1994-1995), II, p. 42.
}

42 MONFORTE, op. cit., fol. 30v. 
mientras que páginas más adelante puso como excusa el miedo a que se quemaran los carros del "Triunfo" del día siguiente ${ }^{43}$.

Estas relaciones ofrecen un destacado conjunto de reflexiones de sus escritores sobre su propia actividad. En general, son conscientes tanto de la imposibilidad de ofrecer una descripción fiel como de las dificultades para que sus escritos sean creíbles. Lo primero a veces lo achacan a falta de espacio, como hace Miguel de León cuando comenta de las joyas del altar de los jesuitas: "a bulto las voy escriviendo, porque apenas cupieran en un tomo sus particularidades, bien especificadas"; pero lo más frecuente es culpar a la falta de capacidad de la expresión escrita. Es lo que hace, por ejemplo, Lope, cuando para describir unos altares remite a unos poemas que se escribieron sobre ellos, consciente del mayor poder connotativo de la poesía; y Ponce repite varias veces que sin dibujos que los reflejen es imposible hacerse una idea fiel de lo que estos altares fueron: "la traça y edificio de los altares, es imposible explicarse, sin el dibuxo, y con él lo será también el entenderse las disposiciones del adorno y disfrutar algunos de sus elementos". En cuanto a las dudas sobre la credibilidad de lo que se escribe, actúan muchas veces en el fondo como recurso estilístico de carácter ponderativo. Monforte las expresa varias veces, como cuando al describir el altar de los dominicos asegura que su relación "parecerá encarecimiento a quien no lo vio", o cuando comenta: "Común vaggio ( $s i c$, por extravío) de relaciones ser tenidas más por pregones de fantasías propias, que de hechos ajenos" ${ }^{44}$.

Lope de Vega hace algunas reflexiones particulares sobre el género de las relaciones. Considera que su lugar dentro de las ciencias históricas es "ínfimo", pues al no remitirse a leyes carece de arte. Las cree "un cuerpo simple a quien falta el alma de las sentencias y el ejemplon, y piensa que deben aspirar a ser "breves, claras y probables". Hay un tono de ironía en su afirmación de que "ya se usan críticos de relaciones como de historias graves".

Los propósitos que están en el origen de la redacción de estas obras son variados. El "Maestro Espino", en su aprobación de la de Lope, declara que el conocimiento de la grandeza con que la Villa de Madrid celebró la canonización de san Isidro despertará "la devoción que merecen sus virtudes y milagros"; y lo mismo viene a decir el rector del Colegio Imperial en su aprobación de la de Monforte. Sin embargo, en el caso de estas dos obras es claro que estamos también ante objetos prestigiadores de quienes las patrocinan.

\footnotetext{
43. Idem, $68 \mathrm{v}$ y $73 \mathrm{v}$.

t4 Ibidem, fols. $27 \mathrm{v}$ y $40 \mathrm{r}$.
} 
Si en muchas ocasiones las relaciones están destinadas sobre todo a lectores ajenos a las fiestas ${ }^{45}$, o a perpetuar su recuerdo entre quienes las vieron, en otras quieren servir también como explicación ordenada de lo que los espectadores percibieron, desordenada y fragmentariamente. También se hacen alusiones iconográficas y de filiación cultural, y se razona la disposición de los diferentes elementos. A esto se refiere Monforte cuando, al justificar lo enormemente prolijo de su descripción del "Triunfo" de la Compañía, asegura que sólo le anima "el cumplir el deseo que tienen muchos de saber la traça y harmonía del paseo", refiriéndose a personas que fueron a verlo pero que no lo entendieron to.

La considerable distancia que existe entre las relaciones de fiestas y la experiencia vivida de los espectadores no radica sólo en las irremediables alteraciones que siempre se producen, al traducir acciones y sensaciones al lenguaje escrito, sino que en muchas ocasiones tiene su origen en la "responsabilidad" del escritor, que le hace ocultar las imperfecciones que pudieran producirse en el transcurso de los festejos, y describe éstos como habían sido proyectados. Es muy difícil detectar ahora estas omisiones, aunque el sentido común y el conocimiento de las leyes que rigen este género literario no dejan lugar a duda de que existieron. En el caso de las fiestas sobre las que tratamos se pueden documentar varias, entre las cuales la más destacada afecta al llamado "Carro de la Fama", una importante obra efímera que Lope de Vega alaba entusiásticamente en su relación, sin comentar que sus defectos de fabricación habían sido tan señalados como para obligar al Ayuntamiento a pagar a su autor 2.000 reales menos de los 5.500 que se habían concertado en un principio ${ }^{47}$.

Resumiendo, podemos decir que el análisis de las obras que describen las fiestas de 1622 permite calibrar grosso modo la distancia entre el desarrollo de las celebraciones y lo que de ellas nos cuentan las fuentes impresas, que han de ser consideradas como género literario con características específicas, cuyo fin primordial no es tanto dejarnos una imagen exacta de la fiesta como inscribirse en el mismo discurso retórico, propagandístico y adulatorio de ésta, y convertir lo que en principio eran actos de naturaleza efímera y sujetos continuamente a imperfecciones, en objetos y ceremonias duraderas que la palabra escrita convierte en perfectos. Lo

45 Dice Diego Ramírez en la aprobación del Certamen angélico de Miranda y la Cotera (Madrid: Diego Díaz de la Carrera, 1657): “Con este libro, y en otro, que en toda brevedad daré a la prensa, de todos los sermones, altares, disposición, y adorno de las calles, gozarán en relación los que no pudieron verlon.

46 MONFORTE, op. cit., fol. 40r.

47 Archivo de la Secretaría del Ayuntamiento, 2-272-30, fol. 55r-v. 
que el espectador vivía como una sucesión de actos discontinuos, a veces desordenados y en numerosas ocasiones de iconografía y significado incomprensibles, el escritor por medio de su discurso convierte en algo racional y ordenado, cuyo significado frecuentemente explica.

\section{JAVIER PORTÚS PÉREZ}

Mediante la comparación de las fuentes literarias y de archivo que nos han quedado sobre unas importantes fiestas religiosas celebradas en 1622 en Madrid, en este artículo se ha tratado de hacer un estudio valorativo del significado de las llamadas arelaciones de fiestas, y de identificar algunas de las leyes que las rigen.

By means of literary and archive documentation on an important religious festival taken place in Madrid in 1622, this paper tris to make an appraisal on the meaning of the so called "relaciones de fiestas", and to identify some of its laws. 